\title{
Transformative Actions towards Sustainable Development. The Case of Boscoreale Municipality, Italy
}

\author{
Floriana ZUCARO ${ }^{*}$, Gerardo CARPENTIERI ${ }^{1}$ \\ ${ }^{*}$ Corresponding author \\ ${ }^{1}$ University of Naples Federico II, Department of Civil, Architectural and Environmental Engineering, Naples, ITALY \\ E-mail: floriana.zucaro@unina.it, gerardo.carpentieri@unina.it \\ DOI: 10.24193/JSSP.2019.2.04 \\ https://doi.org/10.24193/JSSP.2019.2.04
}

K e y $\mathbf{w}$ o r d s: sustainable land use, urban planning, urban resilience, transformative action, municipal master plan (PUC)

\begin{abstract}
A B S T R A C T
This paper describes the outcomes of the technical-scientific consulting activity carried out by the Department of Civil, Building and Environmental Engineering to draft the Municipal Master Plan of Boscoreale in Campania Region (South of Italy). The Boscoreale case study is significant because this city is located on the slopes of Vesuvius, in an area with a great tourism potential, which is also characterized by high risks due not only to the volcano, but also to pollution and hydrogeological phenomena, and yet compromised in terms of urban, landscape and environmental planning. The proposed methodology developed in our study aims to provide local authorities support in planning and decision-making, especially in the process of dividing the municipal territory into homogeneous urban areas, to define the compatible transformations for each area. The theoretical basis of the methodology is to identify a flexible set of potential transformations, rather than a fixed transformation structure, considering that the evolution of the urban system can be potentially affected by unexpected events. The methodology is intended to define a range of physical configurations in order to protect both the available resources and the existing uses within each area and the surrounding territory. Results show that the set of possible transformations is oriented to optimize land use, for instance, uncompressing areas where urban activities have disproportionately impoverished soil's resources and transforming areas with no agricultural and natural value. In conclusion, the range of compatible and suitable transformations of the areas of the city is defined by a procedure that allows us identify those alternatives of transformation that result to be practicable according to the environmental, historical, geomorphological compatibility as well as to the "demand" expressed in the urban context of reference.
\end{abstract}

\section{INTRODUCTION}

The paper presents the results of the technicalscientific consulting activity carried out by the Department of Civil, Building and Environmental Engineering (DICEA) to draft the Piano Urbanistico Comunale (PUC - Municipal Master Plan) of Boscoreale (Naples, Italy) (hereafter referred to as PUC). It refers to the context in which the needs of urban transformation, aimed at improving the quality of life of the inhabitants, must be reconciled with the wide and complex system of constraints, limits and conditions imposed by the current Provincial and Regional legislation framework and the founding principles of sustainability.

In the last decades, the sustainable urban transformation paradigm has become the new focus of the scientific and professional fields, in addition to indicators and useful procedures deriving from wellestablished researches, designed to support decisionmakers to gain urban sustainability goals at different territorial scales (Gargiulo et al., 2018; Ioppolo et al., 2019; Lützkendorf and Balouktsi, 2017; McCool and Stankey, 2004). The sustainable urban transformation 
can be defined as a multi-dimensional and structural transformation, which can lead urban systems to achieve sustainability goals by integrating different experiences and promoting a rational management and usage of resources (Aina et al., 2019; Elmqvist et al., 2019; Ernst et al., 2016; McCormick et al., 2013). In fact, according to (McCormick et al., 2013) "sustainable urban development is primarily about development in urban areas while sustainable urban transformation is about development or change of urban areas". Therefore, essentially, the concept of sustainable urban transformation includes elements such as territorial identity, valorization of local know-how, the promotion and the maintenance of urban resources. This issue is undoubtedly one of the main technical and scientific challenges linked to urban and territorial transformations, since it requires the development of new instruments of territorial governance that combines environmental protection, the need for relation and exchange and the urban system adaptation to change.

In this historical period, marked by the limited availability of natural resources and the increasing frequency and intensity of natural disasters affecting urban systems (also related to climate change), urban expansion policies have given way to recovery and adaptation practices of the consolidated city, in which urban quality and environmental protection play a fundamental role. In other words, a new culture of transformation takes root: it is aimed at reducing the waste of resources and increasing the resilience of urban systems by respecting and enhancing natural vocations of places and restoring their value (Carter et al., 2015; Gargiulo and Lombardi, 2016; Olazabal, 2017; Bai et al., 2018; Gargiulo et al., 2018).

Even strategic documents, based on the principles of the New Urban Agenda (UN, 2017), constantly emphasize that a sustainable urban development must take into account two key factors: the greater efficiency of resources, especially as regards energy and soil use, and the implementation of transformative actions compatible with the set of resources within each urban system. In this respect, both the European Union and the United Nations have drawn attention to the need for a decrease in energy and soil consumption (Hartmann and Spit, 2016; Papa et al., 2016) considering the continuous increase of demand for electricity in any urban area (Italy, for example, recorded an annual increase of 2.0\%) (TERNA, 2017) and the irreversible loss of 1,00o square kilometers of soil per year due to sealing processes (EEA, 2017).

Moreover, worldwide political agendas, from United Nations Organization to the European Commissions and other non-governmental institutions (e.g. German Advisory Council on Global Change, 2011; JPI Urban Europe, 2015) include sustainable urban transformation among the aims of urban governance (Open Working Group of the General Assembly on Sustainable Development Goals, 2014; UN, 2013).

The essential requirement to implement transformative actions towards sustainability is the preservation of available natural and man-made resources that contribute to the overall wellbeing of each generation (Gargiulo 2009; Zucaro and Morosini, 2018; Iwaniec et al., 2019). Promoting a wise and sustainable use of the available resources means that any significant transformation of existing resources shall be followed by compensatory measures to bring the wealth of such resources almost back to the former status.

One of the main technical and scientific challenges of urban and territorial transformations that require the development of new governance tools is to be able to bring together the need of environmental protection, the demand of relationships and exchanges as well as a good level of openness to change the existing urban systems. This challenge seems to be even more onerous in urban contexts characterized by high vulnerability to natural risks. Due to the lack of natural resources and to more and more common and intense phenomena with high-impact on urban systems (also caused by climate changes) local administrations, as decision-makers, are becoming primarily responsible for urban transformations, taking into account mitigation and adaptation measures to natural risks, looking at international planning experiences. In countries such as Spain, Australia, New Zealand and USA the adoption of strategies oriented to the reduction of national vulnerability has allowed to develop specific hazard adaptation plans at the urban scale (Depietri and McPhearson, 2018; Garrido and Saunders, 2019; Martínez-Graña and Gago, 2018; Saunders et al., 2007). In Italy, indeed, issues related to urban resilience to natural events are hardly visible in urban transformations' governance tools, even though Italy is a fragile country, where the effects of earthquakes, landslides and floods are usually amplified by changes in land use and soil sealing process.

In line with these needs, our study aims to develop a methodology to guide the decision-making process of the PUC by identifying the range of possible transformations and compatible uses of Boscoreale territory. In more detail, this work seeks to fill the gap of developing decision-making support tools oriented to both satisfy transforming demands and preserve nonanthropogenic environments. This lack strongly characterizes the Italian planning practices especially with regard to the preparatory phase for the preparation of a Municipal Plan. This proposed methodology for the division of the municipal territory into homogeneous urban areas so as to optimize land use is the result of research work carried out by the DICEA research group (Gargiulo, 2009), then revised 
and adapted to more effectively respond to the indications of the Campania Regional Urban Planning Law no. 16/2004 and its implementing regulations for drafting the PUC.

The paper is articulated as follows: section 2 describes the study area; section 3 describes the proposed methodology; section 4 describes the main results after applying the proposed methodology to the territory of Boscoreale.

\section{STUDY AREA}

To ensure a good level of sustainability, the territorial and urban transformations need to be developed and planned considering the spatial context and its limits, constraints and conditions of potential transformations, as well as vulnerabilities and risk conditions and, moreover, its peculiar connotations related to landscape and environment. This section aims at providing a concise description of the complex system of constraints and safeguards affecting the municipal area of study. This preliminary frame allows for a more specific and extensive knowledge of the environmental and landscape context conditions where the Municipality of Boscoreale is located. Boscoreale is a town north of Pompeii and Torre Annunziata (Province of Naples) (Figure 1), on the slopes of Vesuvius, in an area whose potential attraction level (linked to the presence of archaeological sites among the most famous in the world) is compromised in terms of urban, landscape and environmental planning, with strong risks deriving not only from the proximity to the Vesuvius, but also from the pollution of the Sarno river and the hydrogeological instability phenomena.

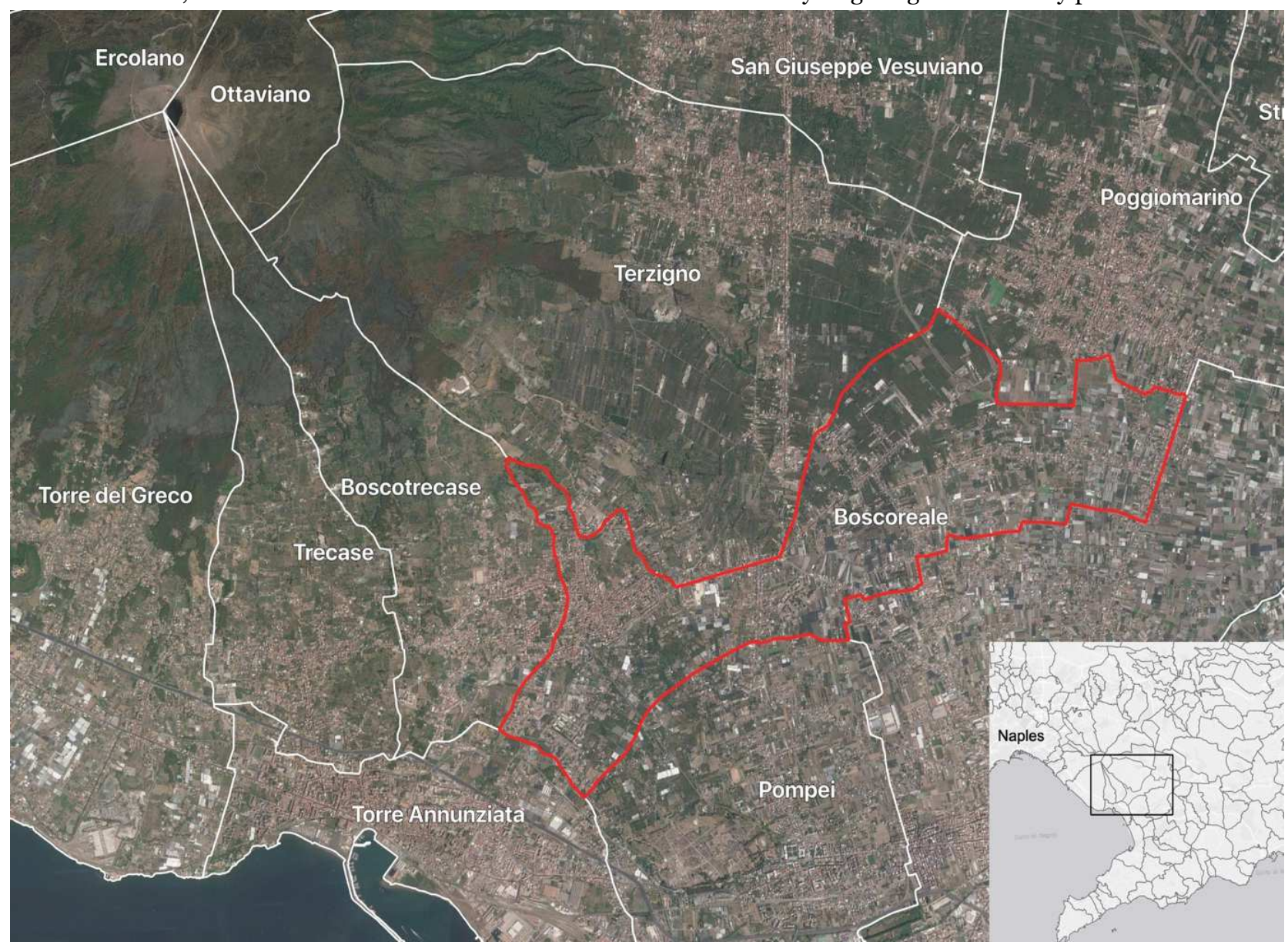

Fig. 1. Location of Boscoreale Municipality (Province of Naples).

The volcanic risk is certainly one of the most urgent matters to be addressed for the area of Boscoreale. Following the update of the eruption scenario for the drafting of the National Emergency Plan for Vesuvius (2012), the Municipality of Boscoreale has entirely been included in the "red zone" of Vesuvius, which is the area at the highest risk, which, in case of a volcanic crisis, needs to be evacuated beforehand. The very significant difficulties related to the evacuation of such a densely populated area have prompted Campania Region to approve Law no. 21/2003, aimed at the delocalization of the residential areas from the red zone. This law states that the general implementation planning instruments for these municipalities cannot include provisions to increase construction for residential purposes by expanding the habitable volumes and the settlement density, and that competent administrations may not adopt provisions for the approval or enforceability (in compliance with applicable laws) of the instruments implementing the 
general urban development plans for the municipalities involved, which would consequently increase residential constructions.

Due to the peculiar elements and the landscape value of specific areas, Boscoreale falls entirely within the area of application of Legislative Decree no. 42/2004 (Art. 136) which involves, for the entire municipal territory, the declaration of outstanding public interest and, consequently, provisions for its protection and enhancement. The position of the Municipality on the edge of the Vesuvius National Park, the presence of several Sites of Community Importance (SCI) and Special Protection Areas (SPA) - established mainly for the purpose of protecting the areas of great natural value included in the perimeter of the Vesuvius National Park - and the widespread presence of agricultural lands of considerable value represent Boscoreale's enormous potential. Despite being identified as one of the areas with "the highest ecosystem fragmentation level" by the Regional Territorial Plan, in fact, it is suitable for the construction of "connecting" areas with a strong landscape-environmental value, designed to reduce landscape fragmentation and restore environmental continuity in this area. Not surprisingly, the Provincial Territorial Coordination Plan (Italian acronym: PTCP) has classified most of the agricultural plain of Boscoreale as an agricultural area of special landscape importance for its soils, recognized among the most fertile of the Campania region, which should therefore be highly valued. Finally, with reference to the Landscape Plan of the Vesuvian Municipalities (2002), Boscoreale has assigned some areas mainly for the regeneration, rehabilitation and conservation of both land and existing constructions.

\section{METHODOLOGY}

The proposed methodology aims at supporting the decision-making process of the PUC in designing the allotment of the municipal land into homogeneous urban areas.

The methodology refers to two main aspects linked to the development of practices and techniques to promote actions towards sustainable urban transformations, according to the content of the previous paragraph: (i) the identification of the "critical capital" of natural and man-made resources, which includes intangible resources to preserve; (ii) the definition of actions that match the vocation and the social, environmental and cultural value of transformable resources (non-critical capital).

Before describing the developed methodology, it is worth referring to the Operational Manual of the Regulation no. 5, dated 4 August 2011, the enactment of Campania Region Law 16/2004 on the subject of territorial governance, which introduces the classification of the territory into UTOE (acronym of the Italian "Unità Territoriali Organiche Elementari") namely elementary and homogeneous units of the territorial system, specifying the documents and maps that constitute the structural provisions of the plan. UTOEs' aggregation allows us to identify the areas of transformation defined as "all parts of the urban territory susceptible to sustainable transformation, minimizing soil consumption and preserving or improving the ratio between sealed surface and permeable soil".

For example, the Manual excludes:

- areas subject to a total building ban;

- areas with significant environmental criticalities;

- areas of significant natural, environmental, landscape or cultural and historical value;

- agricultural areas, forests and pasture-lands of prime importance;

- includes as a priority: unsealed areas; urban areas in need of regeneration; abandoned areas; marginal areas of little value.

The areas of transformation, classified according to their specific functions (as stated in the Manual), together with the UTOEs, are preparatory to the partition of the municipal territory into homogeneous urban areas. In fact, the Manual specifically states that the PUC identifies the transformable areas within the areas of transformation for each area, indicating the implementation method and its specific uses, the land and territorial indices, building guidelines, urban, residential and environmental standards, equipment and services.

Unlike the UTOEs, that refer to the characteristics of the territory (such as morphological characteristics of existing built fabric, with particular attention to historical fabrics; natural-environmental characteristics; landscape and functional characteristics), the areas of transformation are identified according to their propensity and susceptibility to change, with respect to their specific functions (productive, residential, commercial, directional/tertiary and mixed) to be considered for the future territorial system plan.

The criteria defined by the Manual, the transformation objectives pursued by the Boscoreale PUC and the wide heritage of historical-archaeological, landscape and environmental resources constituted the operational elements to be integrated into a broader research work (developed by TeMALab, which is part of DICEA) aimed at developing a decision support tool to allow for a sustainable and optimal use of soil resource, taking into account the "natural" transformation needs of an urban area (Gargiulo, 2009; Papa and Gargiulo, 2015).

In practice, the proposed methodology, aimed at guaranteeing sustainability and compatibility of 
possible transformation actions to the soil resource, constitutes the "trait d'union" between traditional academic research activity and the technical-scientific consultancy carried out in support of the Planning Department of the Municipality of Boscoreale. This methodology is divided into two phases.

The first phase is the identification of resources, whose regenerative power is limited and, therefore, they represent the natural and man-made capital, not easily renewable but necessary to guarantee an adequate quality of life for future generations. To detect these resources, it is imperative to define the set of limits, constraints and conditions for territorial transformation that depends both on universally recognized values (sustainability, irreproducibility of territorial resources, etc.), as well as on modes of thought, on the available resources and the demand of each urban system, according to the criteria laid down by the Manual. In other words, this identification system cannot be unique for all urban contexts but must be adapted to each urban system.

The transformability of each part of the urban area is set by limits, constraints and conditions on the basis of values, vocations, resources and community needs that characterize a particular urban context. Each type of area, defined in light of the value of its physical resources, is, therefore, associated with a range of transformations that could be implemented, in compliance with the principle of sustainable soil use. The higher the value of the physical resources spread within an area (which means that the more the value of an area is high), the more the set of potential transformations that can be performed is reduced; viceversa, the lower the value of the resources, the wider the range of possible transformations is.

This approach does not refer to a binding planning, but to a strategy plan, within which (after ensuring the conservation of the critical capital of resources) the range of possible transformations which outlines the possible actions for each type of area - is drawn.

The definition of the possible and compatible transformation actions on that transformable parts of the territory, which is the second phase of the proposed methodology, is, therefore, subordinated to the identification of the limits, constraints and conditions to which each urban system is subject, and to:

- the definition of the transformation objectives pursued by the PUC, in order to favor their full achievement; into UTOEs.

- the articulation of the municipal territory

To fully understand the logic applied to define the areas of urban transformation of the territory of Boscoreale, we must consider the reduced transformative opportunities of the entire municipal territory, described in the previous section.

\section{RESULTS AND DISCUSSION}

Before describing the non-transformable and transformable areas within the territory of Boscoreale, it is appropriate to refer to the strategies and objectives of transformation pursued by the PUC. In line with the vision of the future configuration of the province of Naples (outlined in the Provincial Coordination Plan) oriented towards the decongestion of valuable and densely populated areas or exposed to natural risks (which may affect the safety and development of local resources), the rise in the conditions of liveability and the enhancement of the agricultural, archaeological and natural resources of this municipal territory constitute the main aims of the PUC of Boscoreale. In this regard, the following eight transformation objectives can be pursued depending on the range of eligible interventions:

a). Redevelop the most densely built-up areas, also by relocating activities to manage congestion;

b). Restore and regenerate existing buildings in agricultural areas, with the possibility of expanding volumes and surface areas for agricultural production;

c). Review the basic education system, also through the relocation of existing structures and a better organization of the school buildings network;

d). Refurbish the public areas and buildings (including residential housing) in the localities of Villa Regina and Passanti, through activities of territorial interest;

e). Redevelop the centre and the historical fabric by reorganizing open spaces for residential, commercial and craft activities and rationalizing traffic movement and parking policies;

f). Encourage craft and tourism industries and consolidate the existing production sectors, also through the expansion of the volumes and surfaces available;

g). Safeguard, highlight and promote archaeological sites and environmental resources through actions that realize their full cultural and economic potential;

h). Improve private residential properties by encouraging redevelopment and make existing buildings energy efficient and safe.

Areas placed under constraints (first of all the impossibility to build new residences, based on the Regional Law no. 21) are identified as nontransformable (white-colored in Figure 2), and they are characterized by almost impossible transformations, due to the combined provisions of the more restrictive regulations of the Provincial Territorial Plan and of the Landscape Plan. In these areas, interventions that can directly or indirectly alter or compromise the overall or specific landscape perception are not allowed, as along with measures that involve the elimination or leveling of the existing land terracing. The plots of the municipal 
territory classified as non-transformable are related to the area included between the slopes of Vesuvius, the historical settlement and the area adjoining the historic center (Figure 2). In what concerns the classification of the areas where transformations are allowed, we tried to highlight the limited transformative possibilities of the areas, rather than focusing on the non-

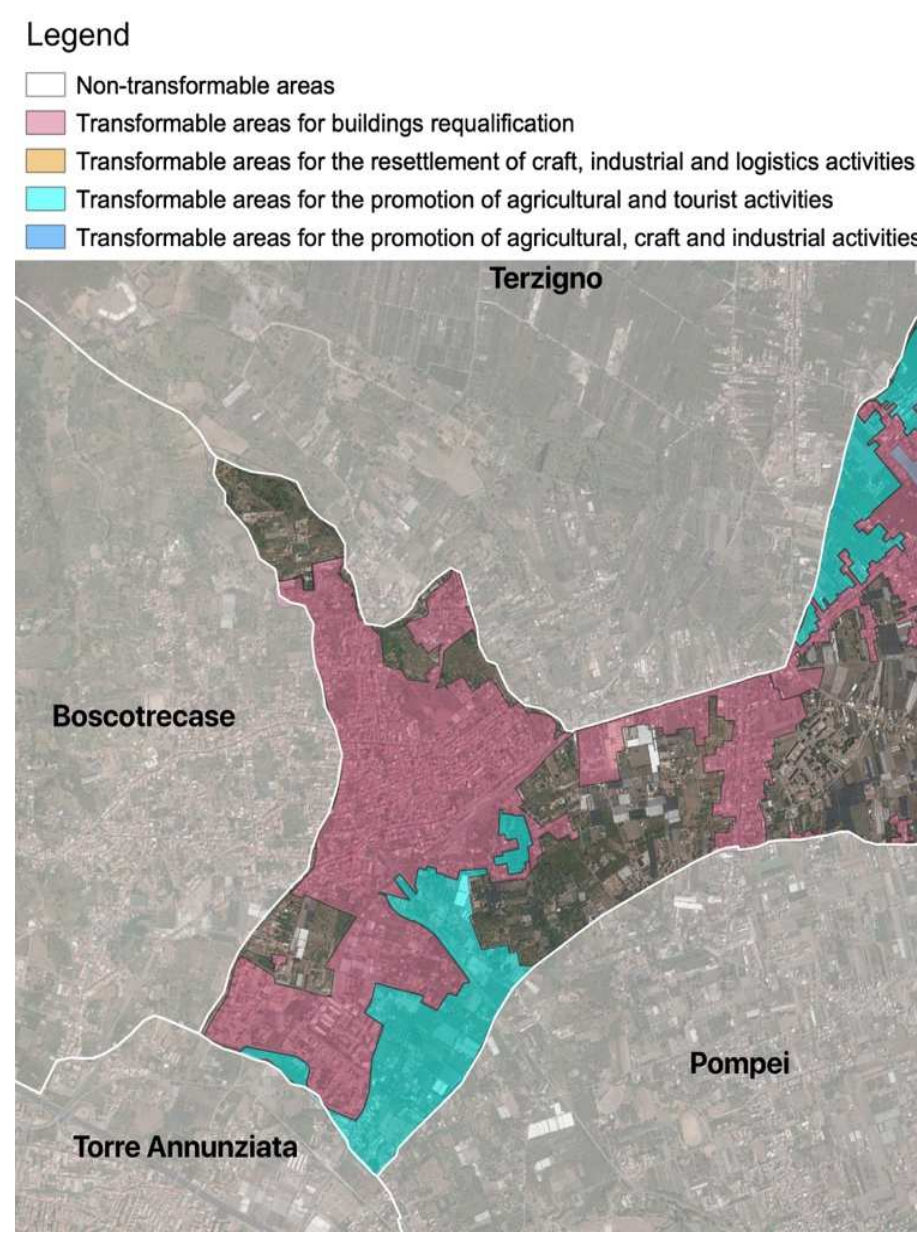

transformable ones. Four categories of transformable areas have been identified, which are essentially defined based on their particular functions, with the explanation of the scarce possibility of transformation compatible with the set of constraints and regulations deriving from Regional and Provincial plans (higher in the planning hierarchy plans).

Fig. 2. The classification of areas in Boscoreale Municipality (non-transformable and transformable).

In particular, the first category of transformable areas is that of the buildings' requalification, in which case the eligible interventions are oriented towards the rehabilitation of the housing stock and provision of greater energy efficiency, without increasing the residential volume layout (as for the whole municipal territory).

The second category includes the resettlement areas of craft, industrial and logistics activities. This category represents the only type of area that can be qualified as transformable in the strict sense, as it includes both the areas where new craft and industrial activities can be established for the processing of agricultural products and those that can be allocated to logistics activities.

The latter could serve not only to the agricultural production carried out within the Municipality of Boscoreale, but also to a wider territory in which agriculture is certainly the most significant and thriving activity. Both activities provide real 116 opportunities for increasing the agricultural income of the city of Boscoreale. The compliance with high soil permeability indices and the use of arboreal and shrubby essences, compatible with the typical essences of the Vesuvius area, constitute the requirements for establishing the activities, in such a way as to reduce the current levels of sealing within the municipal area and enhance the environmental and landscape context. In this respect, Art. 46 of the PTCP provides some opportunities that would increase and incentivize the agricultural income and awards municipal authorities, with the PUC, the task of identifying the areas where rural tourism development and integrative agricultural activities need to be promoted.

The areas of transformation for the production of craft, industrial and logistics activities include the section of the municipal area on the slopes of the Vesuvius, located in the northwest part of Boscoreale, and the area of the linear urban settlement in the northeast part of the town (Figure 2). 
The third category is that of the transformable areas for the promotion of agricultural and tourist activities, for which the eligible interventions are aimed at fostering incentives for the maintenance of such activities and encouraging the revitalization and adaptive reuse of abandoned rural buildings, also for tourism purposes. Moreover, this category would include those areas of the municipal territory for which the PUC must identify the zones intended for the construction of recreational and leisure facilities (such as equipped green areas, sports facilities, etc.), reducing the subtraction of agricultural areas to the barest minimum, in order to preserve the productive and ecosystemic capacities of the soil resource, in accordance with the provisions of the PTCP (Art. 48). Encouraging tourism-related activities, as also foreseen in the territorial governance instruments overarching the PUC, such as the Territorial Plan for the Vesuvian Municipalities and the Strategic and Operational Plan, can therefore be a breeding ground for the promotion of archaeological and natural beauties, both linked to the presence of Vesuvius. The areas of transformation for the promotion of agricultural and tourist activities include the portion of the municipal territory adjacent to the linear urban settlement located to the northeast of Boscoreale and the area located southwest of the town, characterized by the widespread presence of valuable agriculture crops.

The fourth category is that of the transformable areas for the promotion of agricultural, craft and industrial activities, for which the eligible interventions will expand the volume of existing constructions already dedicated to the activities above mentioned.

The identification of the range of interventions for the last two categories of transformable areas allowed for the widespread promotion of the activities envisaged by the Regional and Provincial plans, rather than concentrating new planting activities in small portions of the territory. In particular, for the third category, the transformation relates to the widespread possibilities of developing rural tourism and supplementary agricultural income activities (in accordance with Art. 46 of the PTCP) and creating recreational and leisure facilities, mainly non-built spaces (in accordance with Art. 48 of the PTCP), through reduced volume expansions and/or changes in intended use.

For the fourth category, the transformation relates to the widespread possibility of expanding the volume of existing constructions already dedicated to agricultural, craft and industrial activities.

The areas of transformation for the promotion of such activities include the portions of the municipal territory north of the built-up area that develops almost without interruption - along the west-east line of Boscoreale.

\section{CONCLUSIONS}

The technical-scientific consultancy activity in support of the Municipality of Boscoreale represented an opportunity to apply the methodology developed as part of our research to a case study of particular interest, both for the high vulnerability to natural risks that characterizes this Vesuvian city and imposes restrictions on transformative actions - and for the presence of highly valuable natural, agricultural and landscape features.

The identification of non-transformable territorial capital and of compatible transformation choices aim at building a starting point for any planning hypothesis and urban transformation governance. Hence, they are necessary to design both collective and participatory strategies and options towards urban development, and governance actions to pursue these policy options. This methodology was defined with the main purpose of ensuring that the transformation choices, made by the public decision-makers, were compatible with the set of natural, environmental and historic-cultural values, as well as with the needs of a sustainable land use and the risks arising from natural disasters, especially due to the peculiarities of this territory (ISSC, 2014). From the division of Boscoreale into transformable areas, it can be noted that the range of possible transformations is mainly aimed at enhancing the heritage of existing resources through interventions varying from the expansion of the surfaces dedicated to craft, industrial and tourism activities to the recovery of agricultural activities.

As preparatory to the articulation of the municipal territory into homogeneous urban areas, this work has finally "traced the path" for the definition of "intended uses, eligible interventions, compatible uses and territorial and ecological-environmental endowments" (Art. 2 NTA - Norme Tecniche di Attuazione), namely technical implementation rules aimed at improving the architectural, environmental and settlement quality, the security of homes and workplaces and the living comfort achievable through the set of urban planning provisions for the implementation of the PUC pursuant to the Campania Regional Law no. 16/2004.

\section{REFERENCES}

Aina Y. A., Wafer A., Ahmed F., Alshuwaikhat H. M. (2019), Top-down sustainable urban development? Urban governance transformation in Saudi Arabia. Cities, 90, 272-281. DOI: https://doi.org/ 10.1016/j.cities.2019.03.003

Bai X., Dawson R.J., Ürge-Vorsatz D., Delgado G.C., Barau A.S., Dhakal S., Dodman D., Leonardsen L., Masson-Delmotte V., Roberts, D. (2018), Six research priorities for cities and climate 
change. Nature, 555(7694), 23-25. URL: https://www.nature.com/magazine-assets/d41586018-02409-z/d41586-018-02409-z.pdf. Accessed 29.03.2019

Carter J. G., Cavan G., Connelly A., Guy S., Handley J., Kazmierczak A. (2015), Climate change and the city: Building capacity for urban adaptation. Progress in Planning, 95, 1-66. DOI: https://doi.org/10.1016/j.progress.2013.08.001

Depietri Y., McPhearson T. (2018), Changing urban risk: 140 years of climatic hazards in New York City. Climatic Change 148, 95-108. DOI: https://doi.org /10.1007/s10584-018-2194-2

Di Giovanni G. (2016), Cities at risk: status of Italian planning system in reducing seismic and hydrogeological risks. TeMA - Journal of Land Use, Mobility and Environment, 9(1), 43-62. DOI: https://doi.org/10.6092/1970-9870/3726

EEA (2017), Trends and projections in Europe 2017 Tracking progress towards Europe's climate and energy targets. Publications Office of the European Union: Luxembourg. DOI: 10.2800/791520

Elmqvist T., Andersson E., Frantzeskaki N., McPhearson T., Olsson P., Gaffney O., Takeuchi K., Folke C. (2019), Sustainability and resilience for transformation in the urban century. Nature Sustainability, 2(4), 267. DOI: https://doi.org/10.1038/ s41893-019-0250-1

Ernst L., de Graaf-Van Dinther R. E., Peek G. J., Loorbach D. A. (2016), Sustainable urban transformation and sustainability transitions; conceptual framework and case study. Journal of Cleaner Production, 112, 2988-2999. DOI: http://dx.doi.org/10.1016/j.jclepro.2015.10.136

Gargiulo C., Battarra R., Tremiterra M.R. (2018), Climate change and coastal cities. A GIS-based methodology for facing sea-level rise. In: Leone A., Gargiulo C. (eds.) Environmental and territorial modelling for planning and design. 52-55. Naples: FedOAPress. ISBN: 978-88-6887-048-5, DOI: 10.6093/978-88-6887-048-5

Gargiulo C. (2009), Tecniche per il governo delle trasformazioni: le decisioni. In Papa, R. (ed.) Il governo delle trasformazioni urbane e territoriali, Franco Angeli, Milano, 225-241.

Gargiulo C., Lombardi C. (2016), Urban Retrofit and Resilience. The challenge of Energy Efficiency and Vulnerability. TeMA. Journal of Land Use, Mobility and Environment, 9,(2), 137-162. ISSN 1970-9870. DOI:http://dx.doi.org/10.6092/1970-9870/3922.

Gargiulo C., Sforza A., Sterle C., Zucaro F. (2018), An Optimization Model Fitting the Neighborhood Sustainability Assessment Tools. Sustainability, 10(10), 3365. DOI: http://dx.doi.org/ 10.3390/su10103365

Garrido J., Saunders W. S. A. (2019), Disaster Risk Reduction and Land Use Planning: Opportunities to
Improve Practice. In: Shakoor A., Cato K. (eds) IAEG/AEG Annual Meeting Proceedings, San Francisco.Springer, 5, 161-165. DOI: https://doi.org/ 10.1007/978-3-319-93136-4_20

German Advisory Council on Global Change (2011), World in Transition - A Social Contract for Sustainability. Berlin, Germany: WBGU. URL: https://www.wbgu.de/en/publications/publication/wo rld-in-transition-a-social-contract-for-sustainability.

Accessed on 17.09.2019

Hartmann T., Spit T. (2015), Implementing European climate adaptation policy. How local policymakers react to European policy. TeMA. Journal of Land Use, Mobility and Environment, 8(1), 51-68. DOI: https://doi.org/10.6092/1970-9870/2918

International Social Science Council (ISSC) (2014), Transformations to Sustainability. URL: http://www.worldsocialscience.org/documents/calltransformative-knowledge-network-porposals.pdf.

Accessed on 01.02.2019

Ioppolo G., Traverso M., Finkbeiner M. (2019), Preface-a new paradigm for life cycle thinking: exploring sustainability in urban development scenarios. The International Journal of Life Cycle Assessment, 1-5. DOI: https://doi.org/10.1007/s11367019-01586-X

Iwaniec D.M., Cook E.M., Barbosa O., Grimm N.B. (2019), The framing of urban sustainability transformations. Sustainability, 11(3), 573. DOI: https://doi.org/10.339o/su11030573

Joint Programming Initiative Urban Europe (JPI) (2015), Joint Programming Initiative Urban Europe - Global Urban Challenges, Joint European Solutions. URL: http://jpi-urbaneurope.eu/category/ projects/. Accessed on 17.09.2019

Lützkendorf T., Balouktsi M. (2017), Assessing a sustainable urban development: Typology of indicators and sources of information. Procedia Environmental Sciences, 38, 546-553. DOI: https://doi.org/10.1016/j. proenv.2017.03.122

Martínez-Graña A. M., Gago C. (2018), Environmental analysis of flood risk in urban planning: a case study in Las Quemadillas, Córdoba, Spain. Environmental Engineering \& Management Journal, 17(11). ISSN: $1843-3707$

McCool S. F., Stankey G. H. (2004), Indicators of sustainability: Challenges and opportunities at the interface of science and policy. Environmental Management, 33, 294-305. DOI: https://doi.org/ 10.1007/s00267-003-0084-4

McCormick K., Anderberg S., Coenen L., Neij L. (2013), Advancing sustainable urban transformation. Journal of Cleaner Production, 50, 1-11. DOI: https://doi.org/10.1016/j.cities.2019.03.003

Olazabal M. (2017), Resilience, sustainability and transformability of cities as complex adaptive systems. In Urban Regions Now \& Tomorrow (pp. 73-97). 
Springer, Wiesbaden. DOI: https://doi.org/10.1007/ 978-3-658-16759-2_4

Open Working Group of the General Assembly on Sustainable Development Goals (2014), Open Working Group Proposal for Sustainable Development Goals. New York, USA: Open Working Group of the UN General Assembly on SDG's. URL: https://sustainable development.un.org/content/documents/1579SDGs\%2 oProposal.pdf Accessed on 17.09.2019

Papa R., Gargiulo C., Zucaro F., Cristiano M., Angiello G., Carpentieri G. (2016), Energy and Climate Change Polices in Europe: Overview and Selected Examples from a Spatial Planning Perspective. In Smart Energy in the Smart City. Springer, Cham. 237-274.

Saunders W. S. A., Forsyth J., Johnston D. M., Becker J. (2007), Strengthening linkages between land-use planning and emergency management in New Zealand. The Australian Journal of Emergency Management 22(1), 36-43.
TERNA (2017), Roma: Terna. URL: https://www.terna.it/it-it/sistemaelettrico/statistiche eprevisioni/levoluzionedelmercatoelettricotuttiidati.asp $\mathrm{x} \#$ !\#tab-1. Accessed on 04.05.2019

United Nations (UN) (2017), New Urban Agenda. Washington, DC: United Nations. URL: https://ec.europa.eu/regional_policy/en/policy/theme s/urban-development/agenda/.Accessed on 04.05.2019 UN Sustainable Development Solutions Network (UN) (2013), The Urban Opportunity: Enabling Transformative and Sustainable Development. Bangalore, India. New York, USA: UN Sustainable Development Solutions Network. URL: https://sustainabledevelopment.un.org/content/docum ents/2579Final-052013-SDSN-TGo9-The-UrbanOpportunity.pdf. Accessed on 16.09.2019

Zucaro F., Morosini R. (2018), Sustainable land use and climate adaptation: a review of European local plans. TeMA. Journal of Land Use, Mobility and Environment, 11(1), 7-26. DOI: https://doi.org/ $10.6092 / 1970-9870 / 5343$ 